\title{
Critical Risk Factors in Outsourced Support Projects of IT
}

\author{
Saeed Gholami \\ Graduate Research Student, Doctoral of business administration (DBA) \\ Multimedia University, Malaysia \\ Tel: 60-13-698-7606Ｅ-mail: gholami.mmu@gmail.com
}

Received: September 8, 2011 Accepted: September 24, 2011 Published: January 1, 2012

doi:10.5296/jmr.v4i1.939ＵRL: http://dx.doi.org/10.5296/jmr.v4i1.939

\begin{abstract}
The purpose of qualitative in this study is determining the critical risk factors in the Information Technology (IT) projects outsourcing as well as determine which element of risk factors has more strength and direction with the information technology outsourcing. This study is operating within the constructivism philosophical posture, utilizing interpretive epistemology and induction theory as the approach of research, applying qualitative research methods as well the case study is the relevant research strategy. This study focuses on semi structured interview for suitable data collection to finding financial risks, technical risks, managerial risks, behavioural risks, and Legal and political risks are five categories of critical risk factors in ITO. The research has addressed low awareness of Risk Management activities within public and private sector organizations, and using from the simple method for risk assessment in outsourced of IT. Hence, this study pointed up common language in the area of Risk Management to facilitate communication among vendors and client as two main sources of ITO agreement.
\end{abstract}

Keywords: Critical risk factors (CRF), Information Technology (IT), Outsourced support projects, Case study 


\section{Introduction}

Because of the progress of technology, organizations depend more and more on information technology in order to stay survival and competitive. Therefore, there is a growth of IT outsourcing (ITO) activities particularly for non IT organizations. There are many kinds of IT outsourcing namely facility management outsourcing, complete outsourcing, and system integration outsourcing. Vast majority of these outsourcing projects are reported facing with risk due to the technology and market shift when exercising information technology outsourcing.

The paper continue to be assailed with reports about how difficult software and hardware projects are to manage within time, relationship between vendors and clients, and budget, as well about the costs of failure or under delivery on these projects(Tiwana and Keil 2004).Many companies have turned to outsourcing, either contracting specialist IT companies for custom development work or choosing to install a packaged solution in an attempt to minimize or transfer the risk, but these options, too, seem to be fraught with difficulties(Taylor 2006).

The study organizes in five main parts. The first part presents the study plan for determine the critical risk factors in the Galaxy company as real case. In this chapter illustrated introduction regarding to the importance of the study and the appropriateness of qualitative method. Part two demonstrates an assessment of the literature surrounding the theoretical structure and framework of the research and the consequences of past investigation. Third part will explain on the research method suggested for conducting the research. A conceptual map for better understanding the relationship presented at the chapter. Part four will focus on data analysis and clear the condition and real situations. Finally, the last chapter will illustrate the conclusions, implications, and recommendations.

\subsection{Background of study}

Pervious researches reclassified the four main viewpoints of IT based on two major approach such as balanced scorecard (BSC) and Project Management Body of Knowledge( PMBOK)(ANSI. and PMI. 2004; Van Grembergen, Saull et al. 2004). They are managerial, technical, social, and future-oriented Viewpoints. The managerial viewpoint focuses on the meaning whether the project to be operated is how fit to aims and business strategies of organization, and of management after developing System in order to complete the project successfully, The technical viewpoint highlighting the meaning of technical effort needed in order to get the quality and result which customers satisfy with, the social Viewpoint illustrating efforts to keep the relationships of all stakeholders well, and meaning of managerial element in all involvers like organization and customers the team who are operating the project, and finally, future-oriented Viewpoint considers the managerial item of 
knowledge and techniques, re-education of the team, derived technique and ability improvement of human resources(Kim and Kyung 2007).

And also the earlier studies pointed up the various indices for these viewpoints. For example, Business value, Risk of business, technology movement analysis, team management administration support, project worth, market share, executive contract, labor cost, maintenance, reserve fund, project estimate, team construction, delivers management, talent employment are important indicators for managerial viewpoint(Edberg 1997; Bakos 1998; Martinsons, Davison et al. 1999; Barua and Mukhopadhyay 2000; Mahmood and Mann 2000; Pisello 2001; Gold 2002; Seddon, Graeser et al. 2002; Van Grembergen, De Haes et al. 2004; Reyck, Grushka-Cockayne et al. 2005; Raymond and Bergeron 2008).

For technical viewpoint, important indicators are web site, Requirement analysis, scope definition and plan, scope verification, change, and control, resource assessment, term estimation, time control, risk identification, analysis and evaluation, monitoring, and management plan, verification on product, product confirmation(Edberg 1997; Martinsons, Davison et al. 1999; Barua and Mukhopadhyay 2000; Gold 2002; Seddon, Graeser et al. 2002; Van Grembergen, De Haes et al. 2004; Raymond and Bergeron 2008)

Significant indices in the social viewpoint that prior researches focused on them are communication with user, User participation and satisfaction, executive's support, technical ability of PM and leader ship it, operation of project, support team, teamwork, role and responsibility(Edberg 1997; Martinsons, Davison et al. 1999; Barua and Mukhopadhyay 2000; Gold 2002; Seddon, Graeser et al. 2002; Van Grembergen, De Haes et al. 2004; Raymond and Bergeron 2008).

And finally, the indicators of future-oriented Viewpoint include Documentation, knowledge management system, new technology development, estimate and period of new technology development, derived technology research, technical personnel maintenance, and education program(Martinsons, Davison et al. 1999; Barua and Mukhopadhyay 2000; Gold 2002; Seddon, Graeser et al. 2002; Van Grembergen, De Haes et al. 2004; Raymond and Bergeron 2008).

\subsection{Problem statement/issue}

This study contributes to solving the three main problems in ITO. The first problem is low awareness of Risk Management activities within public and private sector organizations that IT mangers and investors cannot predicate relevance element in this area. The second problem is shortage of a "common language" in the area of Risk Management to facilitate communication among IT investors, managers, clients, and vendors that may create a various perspectives in ITO. The finally challenge is lack of surveys on existing methods, tools and good practices, as well no set up a standard method in outsourced agreements of IT projects. Hence, it is more important to know which of the many possible risks are most likely to cause problems, either because they are difficult to mitigate or because they are difficult to anticipate.

\subsection{Objectives of the project}


The purpose of qualitative in this study is using semi-structured interview that adopt for suitable data collection the critical risk factors in the IT projects outsourcing, as well as the explore which element of risk factors has more strength and direction with the ITO. The end results of this research should lead to a deeper understanding of Risk assessment in outsourced IT projects, as well as some meaningful implications for leaders and senior managers in public and service sectors.

\section{Literature review}

Risk has been defined as a measure under uncertainty of the severity of a hazard(Hoj and Kroger 2002; Suddle 2009), or a measure of the likelihood and severity of adverse effects(Haimes 2009). In general, risk would be defined as an attribute of essence or processes, which may potentially cause damage and harm(Hoj and Kroger 2002). In other word, risk is the product of probability time impact or equal likelihood *impact (OHSAS 18001:2007). The evaluation of IT risk determine as a product of three main factors, including asset value, vulnerability, and threat or equal threat * vulnerability * asset(Vacca 2009).

The previous studies addressed some important evidences, including of the $\$ 2.5$ trillion spent on IT during 1997-2001, nearly \$1 trillion was wagered on underperforming projects(Benko and McFarlan 2003). A large number of underperforming projects ultimately fail, costing U.S. companies more than $\$ 75$ billion each year (Gemino, Horner et al. 2006)[8]. While some events cannot be predicted or controlled, many of the risks that repeatedly plague IT projects can be assessed and managed(Tiwana and Keil 2004). Here the study focuses on the main scenarios that cover the objectives of study like highlighting the critical risks in outsourced IT projects.

\subsection{Features of IT Project}

It is difficult for information technology projects to prescribe obviously necessity and expectation of project clients in the starting step. Therefore, it is also difficult to be said regarding the precise volume of the project, scope of job, cost determination. Particularly the IT project always needs fresh methods and techniques as well there should be a process and system that matching the changing of methods from the project progress in the case of long-term projects(Kim and Kyung 2007). Pervious researches pointed out that IT projects are more difficult than non-IT projects(McDonald 2001; Kim and Kyung 2007). The bellow table lists the major differences of IT projects and non-IT projects.

\section{Figure-1}

\subsection{Motivations to Outsourced of IT projects}

There are several strong business drivers that create motivation to outsourcing IT project. According to a study's outcomes, almost 75 percent of IT projects identified cost reduction as a primary indicator to outsourcing. The following figure shows the various drivers of motivation to IT projects outsourcing(Krishnamurthy, Jegen et al. 2009).

\section{Figure-2}




\subsection{The common Model in ITO}

There are three main models contribute in the ITO, including governance based model, project based model, and pricing based model. The governance model is based on the strategy adapted to control and organizing projects and related teams, the pricing model focuses on price, where the defining guideline are the payments to vendors or the pricing of the work order, and the project based model is combination of both governance and pricing models. Because of the relationship between vendors and clients in the ITO projects, study has special looking on the pricing based model. Today, vast majority of companies using from different kinds of pricing models like time and material managed capacity and fixed price agreements of projects(Krishnamurthy, Jegen et al. 2009).

\subsection{Intractable problems}

A recent survey of MIS directors has highlighted six factors (use of an inappropriate methodology, lack of customer involvement, lack of formal management practices, dissimilarity to previous projects, project complexity, and requirements volatility) that these experienced managers rated most important in risk assessments of their projects(Tiwana and Keil 2004; Taylor 2006). Most of these risks also apply to outsourced custom or package projects, but recent research suggests that there are some unique risks for clients of outsourced projects, arising from possible difficulties in controlling the vendor involvement (Choudhury and Sabherwal 2003), and in managing working relationships between vendor and client(Natovich 2003). Two risks in particular, overoptimistic schedules and budgets and inflated client expectations, are critically important for both vendors and clients considering outsourced projects. Both of these risks arise from the vendor's desire to win business in a highly competitive marketplace(Taylor 2006).

\section{Figure-3}

\subsection{Unforeseen problems}

Client relationship problems appeared unlikely to be expected at the start, partly because signs that such problems might occur are typically not evident early in the vendor- client relationship, and also because their intangible nature makes them difficult to quantify and assess. Project managers would be well advised to pay attention to relationship issues both with their client and within their own team at the start of the project, and to take steps to ensure those relationships are well founded right from the start. The client expectations factor was also a key factor in "troubled" projects, as seen by a number of respondents as one of the key areas for managing risk.

\section{Figure-4}

\subsection{Company profile}

Galaxiq Company established in 2010 with online approach for e Commerce. The fundamental objective of the company is run e business in virtual world. Online E learning, Auction, and virtual environment for advertising are three main departments in the company. The Galaxiq's CEO decided using from various outsourcing agreements in the support 
process and projects for various projects such as soft ware programming and development, security of systems, and web site for rapid growth comparing to competitors. Hence, this very important that the company must control each of projects and monitor project progress as well as has needed the assessment and managing the critical risk factors in the outsourced agreement of IT projects.

\section{Methodology}

\subsection{Research paradigm}

One of important interpretive paradigm is constructivism philosophy or paradigm. The main objective of research in social constructivism outlook relies on the participants' view of condition and situation. Therefore, the researchers of constructivist conduct their researches in the field where the contributors work and live in order to obtain the perception what the contributors are saying(Creswell 2007). This study utilizes form the constructivism philosophy or paradigm, because the notion of the paradigm is mainly to the investigation process in all spaces of research. A paradigm is an extremely universal idea of the nature of systematic effort in which a given inquiry is attempted.

\subsection{The role of researcher}

Researcher in the constructivism paradigm structure must attempt to know what is happening, as well consider total of each condition and situation(Bakia 2011). The researcher in this study should manage time, cost, and other limitation issues and will judge pertaining appropriateness between research objective and other components of study such as research paradigm, strategy, approach, related method, and literature review.

\subsection{Conceptual map}

This study aims that using a theory according to the inductive process through collecting data to broad main and sub themes regarding critical risk factors and effective metrologies in outsourced of IT, as well as using from these themes to generalize. Hence, the study suggests the conceptual framework as a primary theory that after considering inductive process stages such as gathering data and information, conducting field studies, analyzing data from themes, looking for broad pattern and generalizations, and making suitable propositions. The following figure suggests as a proposal conceptual framework, as well highlights the main two scenarios.

\section{Figure-5}

\subsection{Research strategy}

Research strategy must be picked as a function of the study condition and situation. There is the specific approach to gather and analyze empirical and experimental related research strategy. Even though each strategy has its own traits, but there is lapping areas, that carry difficulty to the process of strategy(Yin 1994). The paper focuses on case study as main research strategy, because the notions under study are theoretically and the limits of this phenomenon are yet indefinite. One of major advantages of this approach in this study is 
that investigators are able action far beyond the conventional kind of questions like what, how often, how many to exploring queries on what was completed and how. Hence, the main purpose of the cases in this study to explore the critical risk factors and effective metrologies in outsourced of IT.

\subsection{Data collection method}

This study is operating within the constructivism philosophical posture, utilizing interpretive epistemology and induction theory as the approach of research, applying qualitative research methods; as well the case study is the relevant research strategy. The choice of data collection approaches suggests various traditions such as sampling, questionnaire, observation, interview, focus group, and documentation analysis(Easterby-Smith, Antonacopoulou et al. 2004). Therefore, this study focuses on semi structured interview for suitable data collection. In understanding the opinion of respondents about the critical risk factors and effective metrologies in outsourced of IT semi-structured interview adopted, as well as it was the base on questions and important statements drawn from the literature review, because this type of interview creates an opportunity to exploration complicated issues in a relax environment. The selection of the sample was according following table.

\section{Table 1}

The process of interview included IT investors (2 participants), IT manager (2 participants), IT vendor (2 participants), IT staff and non-IT staff ( 2 participants), and IT facilitator (1participants). In this process, the study focused on two scenarios that motioned in the conceptual map, including critical risk factors and effective methodologies in the outsourcing of IT projects.

\section{Findings/analysis}

There are seven main elements in written message and subjects can be listed in the content analysis: terms, characters, paragraphs, themes, concepts, items, and semantics(Berg 2001). The most applicable and frequently employed unit to consider is the theme. By utilizing thematic examination, the interview data was parsed into information-rich citations that finally put into thematic groups(Anderson and Felsenfeld 2003). By classifying the data, significant ideas concerning to these themes then emerged. Fundamental themes were pre-settled by a review of the literature. Analysis identified three core themes, including critical risk factors, effective methodologies, and outsourcing of IT projects. According to the outcome of interview process, the participants expressed the five categories and nineteen criteria as main and sub factors critical risk factors.

The five categories are financial risks (with the three sub factors), Technical risks (with seven sub factors in two hardware risks: data base, maintenance, communication infrastructure, and Software risks: complexity, security, licensing, and standards), Managerial risks (with five sub factors change management, Tasks and responsibility, Distinctive capabilities in IT, Reporting, Decision making), Behavioral risks ( Knowledge sharing, Trust and moral, Team working, Training, Cultural issues), and Legal and political risks (Privacy rule, Law and order tradition, Accountability, Quality of bureaucracy). 
After identifying of the classification of main risk factors, participants through brainstorming assessed the amount of risk pertaining each of sub risk factors. The process of risk assessment focused on failure modes and effects analysis (FMEA) as a method in development of product and operation management for analysis of potential failure modes within a system for classification via likelihood or probability, exposure, and consequence(Tekinerdogan, Sozer et al. 2008). There are several types of FMEA, including process, design, concept, equipment, service, system, and software, however this procedure not enough and complete for each failures (Bidokhti 2009). The outcome of three element leads to the calculation of Risk Priority Number (RPN). This methodology is a technique for analyzing the risk associated with potential problems identified during a Failure Mode and Effects Analysis. The following table shows the results of FAME and rank of risk factors in the outsourced of IT projects.

\section{Table 2}

The high score is related to the budget management, trust and moral, team working, quality of bureaucracy, and security. The bellow graph shows them.

\section{Figure-6}

\section{Discussion and limitations}

This study has highlighted specific critical risk factors that both vendors and clients should be aware of them when entering into in the ITO, and has suggested key classification of main and sub categories for addressing these risks. In particular, budget management, trust and moral, team working, quality of bureaucracy, and security as intractable problems, as well as traditional methodologies of risk assessment in outsourcing of IT projects. These are true for both vendors and client.

In other side, the research has addressed low awareness of Risk Management activities within public and private sector organizations, and using from the simple method for risk assessment in outsourced of IT. This is can be a common language in the area of Risk Management to facilitate communication among vendors and client as two main sources of ITO agreement, as well the study has presented tools and best practice in the outsourced agreements in the IT.

In addition to positive aspects there are also some limitations of used techniques and tools like brainstorming technique that must be taken into consideration. Sometimes brainstorming meetings don't produce results as expected. This is fundamentally for two main reasons, including lack of adhesion with procedures based on experience and overrated expectation(Shneiderman 2007). The major limitations in the study were honest and time. Honesty is one important factor to answering the questions in the interview process. Due to the nature of risk assessment in the ITO activities that has high sensitivity can be affect on respond honestly by the participants. And also the duration of study was very short.

\section{Conclusion}

IT people do not give a real picture to the users about the project challenges, and researchers think that's a major, major problem. The study highlighted five financial, technical, managerial, behavioral, and legal and political risks categories. According to Pareto law, the 
eighty percent of critical problems has root in the twenty percent critical risk factors. The major critical risks in the study are budget management, trust and moral, team working, quality of bureaucracy, and security. These factors have confirmed through previous studies like(Taylor 2006). Highlighting these distinct outsourcing risk factors now opens up several avenues for future outsourcing research. One of issues for future research in ITO can be application effective risk assessment methodologies like the qualitative, the quantitative, and the hybrid techniques (qualitative quantitative, semi-quantitative). The critical risk factors for the Galaxy company lead to undesirable outcomes such as the enhanced cost of services, costly contractual changes, disputes and litigation, unexpected transition and management expenditure, and loss of company competencies.

The paper suggests $4 \mathrm{~T}$ as comprehensive approach to managing the risk in the ITO. The four Ts approach consist of Tolerate (Decide to live with the risk, the possibility that it might occur and its possible consequences), Transfer (Some of the financial risk may be transferred through insurance and it may be possible to transfer liability through contractual arrangement), Terminate (Eliminate the risk, usually by deciding to avoid a course of action or stop a particular activity), and Treat (the treat includes two elements. Containment is the application of measures to reduce either probability or impact; contingency is the action to take if the event does occur).

Future research the study can utilize quantitative research methods for data collection. The study's design can use of a simple random sampling technique provided a study specimen of various demographic segments representing the target population. The survey tool will be developed to provide as the basis for collecting data pertaining to five financial, technical, managerial, behavioral, and legal and political risks categories.

\section{References}

Anderson, T. K. and lsenfeld,S.F. (2003). "A thematic analysis of late recovery from stuttering." American Journal of Speech-Language Pathology 12(2): 243.

ANSI. and PMI. (2004). A Guide to the Project Management Body of Knowledge: PMBOK Guide, Project Management Institute, Inc.

Bakia, M. (2011). "Research proposal: Mformor Bakia."

Bakos, Y. (1998). "The productivity payoff of computers." Science(Washington) 281(5373): 52-52. 
Barua, A. and Mukhopadhyay,T. (2000). Information technology and business performance: Past, present, and future, Pinnaflex Press, Cincinnati, OH: 65-84.

Benko, C. and McFarlan,F.W. (2003). Connecting the dots: Aligning projects with objectives in unpredictable times, Harvard Business Press.

Berg, B. L. (2001). "Qualitative research methods for the social sciences."

Bidokhti, N. (2009). FMEA is not enough, IEEE.

Choudhury, V. and Sabherwal, R. (2003). "Portfolios of control in outsourced software development projects." Information Systems Research 14(3): 291.

Creswell, J. W. (2007). Qualitative inquiry \& research design: Choosing among five approaches, Sage Publications, Inc.

Easterby-Smith, M., Antonacopoulou, E., Simm, D., Lyles, M. (2004). "Constructing contributions to organizational learning." Management Learning 35(4): 371.

Edberg, D. T. (1997). "Creating a balanced IS measurement program." Information Systems Management 14(2): 32-40.

Gemino, A., Horner, B., Sauer, C. (2006). "Factors Influencing IT Project Performance."

Gold, R. S. (2002). "Enabling the strategy-focused IT organization." Information Systems Control Journal 4: 21-24.

Haimes, Y. Y. (2009). Risk modeling, assessment, and management, Wiley.

Hoj, N. P. and Kroger, W. (2002). "Risk analyses of transportation on road and railway from a European Perspective." Safety Science 40(1): 337-357. 
Kim, S. and Kyung, T. (2007). A study on the priority selection for information system project management model, World Scientific and Engineering Academy and Society (WSEAS).

Krishnamurthy, K., Jegen, D., Brownell, B. (2009). "Strategic Out-Tasking: Creating." Information \& Management 46(1): 42-51.

Mahmood, M. A. and Mann, G.J (2000). "Special issue: impacts of information technology investment on organizational performance." Journal of Management Information Systems 16(4): 3-10.

Martinsons, M., Davison, R., Tse, D. (1999). "The balanced scorecard: a foundation for the strategic management of information systems." Decision Support Systems 25(1): 71-88.

McDonald, J. (2001). "Why is software project management difficult? And what that implies for teaching software project management." Computer Science Education 11(1): 55-71.

Natovich, J. (2003). "Vendor related risks in IT development: A chronology of an outsourced project failure." Technology Analysis \& Strategic Management 15(4): 409-419.

Pisello, T. (2001). Return on Investment for Information Technology Providers, Information Economics Press, New Canaan.

Raymond, L. and Bergeron, F. (2008). "Project management information systems: an empirical study of their impact on project managers and project success." International Journal of Project Management 26(2): 213-220.

Reyck, B.D., Grushka-Cockayne, Y., Lockett, M., Calderini, S.R.,Moura, M., Sloper, A. (2005). "The impact of project portfolio management on information technology projects." International Journal of Project Management 23(7): 524-537.

Seddon, P.B., Graeser, V., Willcocks, L.P. (2002). "Measuring organizational IS effectiveness: an overview and update of senior management perspectives." ACM SIGMIS Database 33(2): 11-28. 
Shneiderman, B. (2007). "Creativity support tools: accelerating discovery and innovation." Communications of the ACM 50(12): 20-32.

Suddle, S. (2009). "The weighted risk analysis." Safety Science 47(5): 668-679.

Taylor, H. (2006). "Critical risks in outsourced IT projects: the intractable and the unforeseen." Communications of the ACM 49(11): 74-79.

Tekinerdogan, B., Sozer, H., Aksit, M. (2008). "Software architecture reliability analysis using failure scenarios." Journal of Systems and Software 81(4): 558-575.

Tiwana, A. and Keil,M. (2004). "The one-minute risk assessment tool." Communications of the ACM 47(11): 73-77.

Vacca, J. R. (2009). Computer and information security handbook, Morgan Kaufmann.

Van Grembergen, W., De Haes, S., Guldentops, E. (2004). "Structures, processes and relational mechanisms for IT governance." Strategies for information technology governance: $1-36$.

Van Grembergen, W., Saull, R., De Haes, S. (2004). "Linking the IT balanced scorecard to the business objectives at a major Canadian financial group." Strategies for information technology governance: 129 .

Yin, R. K. (1994). "Case study research: design and methods, Applied Social Research Methods Series, vol. 5." Thousand Oaks: Sage 1(2): 3.

\section{Biography of Author}




\section{Macrothink

Saeed Gholami is a graduate research student on the faculty of management, Multimedia University, Malaysia. He has more than 23 years teaching, research and professional experience and published numerous papers in international refereed journal in the defferent area of DBA. 